\title{
Peer-driven contraceptive choices and preferences for contraceptive methods among students of tertiary educational institutions in Enugu, Nigeria
}

This article was published in the following Dove Press journal:

Patient Preference and Adherence

3I July 2014

Number of times this article has been viewed

\section{CA lyoke' \\ FO Ezugwu² \\ OL Lawani ${ }^{3}$ \\ GO Ugwu' \\ LO Ajah ${ }^{3}$ \\ SG Mba'}

'Department of Obstetrics and Gynecology, University of Nigeria Teaching Hospital, Enugu, ${ }^{2}$ Department of Obstetrics and Gynecology, Enugu State University Teaching Hospital, Enugu; ${ }^{3}$ Department of Obstetrics and Gynecology, Federal Teaching Hospital, Abakaliki, Nigeria
Correspondence: Chukwuemeka Anthony lyoke

Department of Obstetrics and Gynecology, University of Nigeria Teaching Hospital, PO Box 4994, Ituku-Ozalla, Enugu 40000 I, Nigeria

Tel +234808583 I I67

Email caiyoke@yahoo.co.uk
Purpose: To describe the methods preferred for contraception, evaluate preferences and adherence to modern contraceptive methods, and determine the factors associated with contraceptive choices among tertiary students in South East Nigeria.

Methods: A questionnaire-based cross-sectional study of sexual habits, knowledge of contraceptive methods, and patterns of contraceptive choices among a pooled sample of unmarried students from the three largest tertiary educational institutions in Enugu city, Nigeria was done. Statistical analysis involved descriptive and inferential statistics at the $95 \%$ level of confidence.

Results: A total of 313 unmarried students were studied (194 males; 119 females). Their mean age was $22.5 \pm 5.1$ years. Over $98 \%$ of males and $85 \%$ of females made their contraceptive choices based on information from peers. Preferences for contraceptive methods among female students were $49.2 \%$ for traditional methods of contraception, $28 \%$ for modern methods, $10 \%$ for nonpharmacological agents, and $8 \%$ for off-label drugs. Adherence to modern contraceptives among female students was $35 \%$. Among male students, the preference for the male condom was $45.2 \%$ and the adherence to condom use was $21.7 \%$. Multivariate analysis showed that receiving information from health personnel/media/workshops (odds ratio 9.54, 95\% confidence interval 3.5-26.3), health science-related course of study (odds ratio 3.5, 95\% confidence interval 1.3-9.6), and previous sexual exposure prior to university admission (odds ratio $3.48,95 \%$ confidence interval 1.5-8.0) all increased the likelihood of adherence to modern contraceptive methods.

Conclusion: An overwhelming reliance on peers for contraceptive information in the context of poor knowledge of modern methods of contraception among young people could have contributed to the low preferences and adherence to modern contraceptive methods among students in tertiary educational institutions. Programs to reduce risky sexual behavior among these students may need to focus on increasing the content and adequacy of contraceptive information held by people through regular health worker-led, on-campus workshops.

Keywords: modern contraceptives, preference, young people, sexual behavior

\section{Introduction}

The United Nations defines young people as those aged 15-24 years. ${ }^{1}$ Across the world, students in higher institutions of learning constitute an influential group of young people. Studies from South East Nigeria have shown that the level of sexual activity among young people in tertiary educational institutions is high, ${ }^{2}$ and that complicated illegally induced abortion for unwanted pregnancy has increased five-fold over the previous decades with significant abortion-related mortality. ${ }^{3,4}$ In addition, Enugu state has one of the highest rates of human immunodeficiency virus infection among pregnant women in Nigeria. ${ }^{5}$ Given the restrictive abortion laws in place in Nigeria, 
efforts at reversing the trend towards high rates of unwanted pregnancy, unsafe abortion, and human immunodeficiency virus infection among young people relies upon increasing the uptake of contraception, in particular the more effective modern methods.

The World Health Organization lists modern methods of contraception as oral contraceptives, injectable contraceptives, implants, intrauterine devices, male and female condoms, male and female sterilization, lactational amenorrhea method, and emergency contraception. ${ }^{6}$ Similarly, the World Health Organization's list of traditional contraceptive methods includes the withdrawal method and fertility awareness methods, including calendar-based methods - monitoring fertile days in the menstrual cycle, and symptom-based methods - monitoring cervical mucus and body temperature. ${ }^{6}$

Anecdotal evidence shows that the habits of students in tertiary institutions in Nigeria significantly influence other young people in their society who tend to take social cues from undergraduate students. Any pattern of reproductive health behavior among university students could therefore have a profound effect on young people in the society generally. Meanwhile, several studies have documented risky sexual habits of Nigerian undergraduates ${ }^{6-8}$ and have shown that some undergraduates resort to nonpharmacological agents and off-label drug use for contraception. ${ }^{9-11}$ However, little is known about the factors that drive the trends in contraceptive preferences. Knowledge of the factors that drive contraceptive preferences and adherence of young people in tertiary institutions could be useful for programs aimed at reducing risky sexual behavior, unwanted pregnancy, and unsafe abortion. The aim of this study was to describe the methods preferred for contraception, evaluate preferences for and adherence to modern contraceptive methods, and determine the associated factors among students in tertiary educational institutions in Enugu, South East Nigeria.

\section{Methods}

This study was conducted in three tertiary educational institutions in Enugu city, namely Enugu State University of Science and Technology, Institute of Management and Technology Enugu, and the University of Nigeria Enugu Campus. Each of these schools has at least one campus in the heart of the capital city of Enugu State. There are a lot of commercial as well as social activities around the premises of these campuses. Nigerian students are drawn from all parts of Nigeria irrespective of sex, ethnicity, or religion. Students are allowed free social interaction both within and outside the school campuses and are therefore tremendously influenced by social lifestyles within the city. This was a cross-sectional study that took place between October and December 2013.

Sampling was by multi-stage sampling. The first stage involved a purposive sample of the three largest tertiary educational institutions in Enugu city. For the second stage, a hostel in each of the selected schools was chosen by simple random sampling using an enclosed bag containing the names of all the hostels in the school that are located within Enugu city. The third stage involved systematic random sampling using the list of rooms in each hostel as a sampling frame. A room number was chosen randomly using a table of random numbers. Subsequently, every second room in increasing room numbers from the random start was selected and all consenting students in each room who met the inclusion criteria were administered with questionnaires.

A semi-structured anonymous questionnaire developed for the study served as the data collecting tool. Data collection lasted for 8 weeks spanning from October 15 to December 15, 2013. Trained research assistants assisted with the distribution of the questionnaires. Given the confidential nature of some of the questions, it was decided that students be approached in the living rooms mostly on weekends. Permission to share questionnaires was obtained from hall wardens. Respondents were asked to drop their filled questionnaires in a common place - a bag left in the hall warden's office - and the research assistants collected them each week.

Sample size was determined using the formula for sample size determination in cross-sectional studies originally described by Daniel ${ }^{12}$ but recently highlighted by Naing et al: ${ }^{13}$

$$
\left(Z_{\alpha / 2}\right)^{2} \mathrm{P}(1-\mathrm{P}) / d^{2}
$$

where $Z$ is the $z$-score for $95 \%$ confidence level, $\mathrm{P}$ is the assumed population prevalence, and $d$ is the $\alpha$ error. Assuming a confidence level of $95 \%$, an $\alpha$ error of $5 \%$, a prevalence of sexual activity among undergraduates in Enugu of $76.4 \%$ based on a previous study in Nigeria, ${ }^{2} Z=1.96, \mathrm{P}=0.8$, and $d=0.05$. The minimum sample size required for the study was 272 .

Inclusion criteria included Nigerian citizenship, single marital status, having spent up to 1 year in a tertiary educational institution, and consent to participate in the study. Exclusion criteria included non-Nigerian citizenship, being married, and refusal to consent to the study.

Data analysis was performed using SPSS $^{\circledR}$ version 15.0 for Windows ${ }^{\circledR}$ (SPSS Inc., Chicago, IL, USA). Preference 
for contraceptive method was defined as the contraceptive method which a student chose for preventing pregnancy and was determined by the question: "Which of the following contraceptive methods did you prefer for the purpose of preventing pregnancy or infection when you had sex?" Those who ticked modern methods, traditional methods, nonpharmacological agents, or noncontraceptive pharmacological agents were tallied and the proportions of those choosing each category were obtained. While the list of modern and traditional methods were based on the World Health Organization's description of modern and traditional methods of contraception, ${ }^{6}$ the list of nonpharmacological agents and drugs used off-label for contraception were based on agents described in previous studies in this area. ${ }^{9,10}$ Adherence to contraceptive use was defined as the use of contraceptives for every sexual exposure, and was determined by the question: "How regularly did you use your preferred contraceptive method during or following sexual exposure?", with answers in a Likert-type scale, including "all the time," "some of the time," and "none of the time." All cases who answered "all the time" were deemed to have adhered to contraceptive use. This answer was related to the preferred contraceptive to determine which of the contraceptive methods the respondent adhered to. Descriptive statistics were used to obtain the prevalence of sociodemographic variables, sexual activity, preferences, and adherence to different contraceptive methods. Tests of association between sociodemographic variables, and preferences for, and adherence to the use of modern contraceptives were done using Pearson's chi-square (and Fisher's exact test where appropriate). Multivariate analysis was done to determine the variables that increased the likelihood of preference for and adherence to modern contraceptive methods. Preference for or adherence to modern contraceptive method was coded as Yes $=1$, while preference for or adherence to all other methods was coded as No $=0$. The results were expressed as adjusted odd ratios with $95 \%$ confidence limits. $P \leq 0.05$ was considered significant.

Ethical clearance was obtained from the Research Ethics Committee of University of Nigeria Teaching Hospital, Enugu.

\section{Results}

A total of 400 questionnaires were distributed; 349 were returned, giving a recovery rate of $87.3 \%$. Of these, 36 students indicated that they were married and were excluded from the study. The responses of 313 unmarried students were analyzed. These included 194 males and 119 females. Their mean \pm standard deviation age was $22.5 \pm 5.1$ years. Table 1 shows the distribution of the sociodemographic characteristics of the respondents.

\section{Sexual activity}

Approximately 85\% (266/313) reported having sexual exposure since admission to school, including 172 males and 94 females; $15 \%$ (47/313) reported no sexual activity. $68.5 \%(182 / 266)$ of the sexually active students $(125 / 172$ males and 57/94 females) had had more than one sexual partner; approximately $7.1 \%$ had had up to five sexual partners. Twenty-five percent (67/266) of the sexually active students had coitus within 1 week preceding the interview. The sexual partners of the male students were fellow students in the same school in $12 \%$ of cases, and friends outside the school in $72 \%$ of cases. For female students, sexual partners were fellow students in the same school in $4 \%$ of cases, and males outside the school in $94 \%$ of cases.

Table I Sociodemographic characteristics of the sample of students from tertiary educational institutions who were interviewed about their use of contraceptive methods in Enugu, Nigeria

\begin{tabular}{|c|c|c|}
\hline $\begin{array}{l}\text { Sociodemographic } \\
\text { characteristic }\end{array}$ & $\begin{array}{l}\text { Frequency, } \\
\text { n (\%) }\end{array}$ & $\begin{array}{l}\text { Response rate } \\
\text { for question }\end{array}$ \\
\hline Age $(n=287)$ & & $91.7 \%$ \\
\hline II-20 years & $60(20.9)$ & \\
\hline $2 \mathrm{I}-30$ years & $215(74.9)$ & \\
\hline $31-40$ years & $10(3.5)$ & \\
\hline $4 I-50$ years & $2(0.7)$ & \\
\hline Religion $(n=3 \mid 2)$ & & $99.7 \%$ \\
\hline Christianity & $290(93.0)$ & \\
\hline Islam & $10(3.2)$ & \\
\hline Traditional religion & $6(1.9)$ & \\
\hline Others & $6(1.9)$ & \\
\hline Christian denomination $(n=290)$ & & $94.1 \%$ \\
\hline Catholic & $127(42.8)$ & \\
\hline Anglican & $66(22.8)$ & \\
\hline Pentecostal & $56(19.3)$ & \\
\hline Others & $24(8.3)$ & \\
\hline Tribe $(n=292)$ & & $94.9 \%$ \\
\hline Igbo & $246(84.2)$ & \\
\hline Yoruba & $26(8.9)$ & \\
\hline Hausa & $4(1.4)$ & \\
\hline Others & $16(5.5)$ & \\
\hline Course of study $(n=308)$ & & $98.4 \%$ \\
\hline Health science related & $173(56.2)$ & \\
\hline Non-health science related & $135(43.8)$ & \\
\hline Level of study $(n=3 \mid 2)$ & & $99.7 \%$ \\
\hline First year & $8(2.6)$ & \\
\hline Second year & $54(17.3)$ & \\
\hline Third year & $69(22.1)$ & \\
\hline Fourth year and above & $|8|(58.0)$ & \\
\hline
\end{tabular}


About 14.2\% (17/119) of the female students reported being pregnant since they became undergraduates, all of whom either practiced traditional methods of contraception or used nonpharmacological agents and off-label drugs for contraception. All resorted to termination of the pregnancy $-10 \%$ by medical methods and $4 \%$ by surgical termination. Approximately $50 \%$ of those who reported pregnancy termination reported complications, including excessive bleeding, infection, and incomplete evacuation. About 14.7\% (14/94) of all sexually active female students reported having sexually transmitted infections since admission to a tertiary educational institution.

\section{Knowledge and preferences for contraception}

Approximately $34 \%$ (91/266) of sexually active students could correctly describe when and how any two modern methods of contraception were used compared to $1.3 \%(6 / 47)$ of sexually inactive students. The difference in the proportions of sexually active and sexually inactive students who had correct knowledge of modern contraceptive methods was statistically significant $(P<0.001)$. Similarly, a higher proportion of male students compared to females were able to correctly describe two modern methods of contraception (39\% versus $25 \% ; P=0.03$ ). Approximately $45 \%$ of female students could correctly describe two traditional methods of contraception (42/94).

Table 2 summarizes the reported sources of information that influenced the contraceptive choices of students. Over $98 \%$ of males and $85 \%$ of females reported peers (friends and sexual partners) as the main sources of their knowledge of contraceptive methods.

Table 2 Major sources of information on contraceptive methods and choices among students of tertiary educational institutions in Enugu, Nigeria

\begin{tabular}{llll}
\hline Student & Source of information & Number & Percentage \\
\hline Females $(\mathrm{n}=94)$ & & & \\
& Friends & 80 & 85.0 \\
& Sexual partners & 61 & 65.0 \\
& Health workers & 40 & 38.0 \\
& Media including internet & 23 & 24.0 \\
& Parents & 22 & 23.3 \\
& Workshop & 7 & 7.5 \\
Males (n=172) & & & \\
& Friends & 169 & 98.0 \\
& Media including internet & 69 & 40.0 \\
& Health workers & 55 & 32.0 \\
& Workshops & 3 & 2.0 \\
\hline
\end{tabular}

The sexual partners of the female students chose the type of contraceptives used by them in about $33.4 \%$ of cases, whereas approximately $52 \%$ of sexually active females made the decision themselves. Of the $45.2 \%$ of sexually active males who used condoms, the decision to use the condom was made independently in $21.2 \%$ of cases and due to insistence by female partners in $24.0 \%$.

Table 3 summarizes the types of contraception preferred by students. Among male students, the preference for condom use was $45.2 \%$ (77/172). Male students who did not use condoms preferred their partners to use some form of contraception. Most female students preferred traditional contraceptive methods such as fertility awareness methods (49\%), whereas $28 \%$ preferred modern (artificial) contraceptive methods. Preferences for traditional methods of contraception were driven by advice from friends and relations in $77 \%$, and the fear of perceived complications of modern (artificial) methods in $23.5 \%$. The main reasons for the preference for nonpharmacological agents and off-label drug use were advice from friends and the cheap cost of agents. A significantly higher proportion of sexually active male students preferred modern contraceptives compared to females ( $45.2 \%$ versus $28 \% ; P=0.01$ ).

\section{Adherence to modern contraceptive methods}

Of the 26 female students who used modern contraceptive methods, about $35 \%(9 / 26)$ reported adherence to

Table 3 Types of contraception used by students

\begin{tabular}{|c|c|c|c|}
\hline Student & $\begin{array}{l}\text { Preferred contraceptive } \\
\text { method }\end{array}$ & Number & Percentage \\
\hline \multicolumn{4}{|c|}{ Females $(n=94)$} \\
\hline & Traditional methods & 46 & 49.1 \\
\hline & Calendar-based methods & 32 & 34.2 \\
\hline & Symptom-based methods & 14 & 14.9 \\
\hline & Modern methods & 26 & 27.7 \\
\hline & Emergency oral contraceptives & 20 & 21.3 \\
\hline & Combined oral contraceptives & 2 & 2.1 \\
\hline & Injectable contraceptives & 2 & 2.1 \\
\hline & Female condom & 2 & 2.1 \\
\hline & Nonpharmacological agents & 9 & 9.6 \\
\hline & Alcohol (stout, spirits) & 2 & 2.1 \\
\hline & Andrews liver salt & 5 & 5.3 \\
\hline & Lime juice & I & 1.0 \\
\hline & Herbal mixtures & I & 1.0 \\
\hline & Off-label drug use & 8 & 8.4 \\
\hline & White quinine & 4 & 4.3 \\
\hline & Misoprostol & 3 & 3.2 \\
\hline & Chloroquine & I & 1.0 \\
\hline \multicolumn{4}{|c|}{ Males $(n=172)$} \\
\hline & Condom & 77 & 44.8 \\
\hline & No condom & 95 & 55.2 \\
\hline
\end{tabular}


contraceptive use, while adherence to traditional methods was $60 \%(28 / 46)$. Of the 77 sexually active male students who used condoms, adherence to condom use was $21 \%(16 / 77)$. The difference in the proportions of female and male students who adhered to modern contraceptive use was statistically significant (35\% versus $21 \% ; P=0.03$ ). Reasons for adherence included opinions such as "modern contraceptives were more effective in preventing pregnancy" (98\%), "modern contraceptives were more effective in preventing infections" (72\%), "their side effects could be tolerated" (35.3\%), and some modern methods were female controlled (5.9\%).

About $34.1 \%$ of sexually active female students wanted to continue using modern contraceptives while $57 \%(15 / 26)$ did not want to continue using them. Among these, the majority wanted to stop using them because they felt "they could cause infertility in future" (35\%), "they could cause cancer" (31\%), and "they were not readily available" (29.6\%). Other reasons were that "they might make them fat" $(18.5 \%)$, "they made them feel that they were promiscuous" $(18.5 \%)$, and "they were costly" (14.8\%).

\section{Factors associated with preference for and adherence to the use of modern contraceptives}

Table 4 shows the results of bivariate analysis to determine the association of sociodemographic variables with preference for modern contraceptive methods. Age group, Christian denomination, course of study, year of study, predominant source of contraceptive information, and previous sexual exposure prior to admission to tertiary educational constitution were significantly associated with a preference for contraceptive methods ( $P<0.01$ for all variables). However, tribe was not associated with a preference for modern contraceptive methods.

Table 5 shows the results of bivariate analysis to determine the association of sociodemographic characteristics with adherence to modern contraceptive methods. Age group, Christian denomination, course of study, predominant source of contraceptive information, and previous sexual exposure prior to admission to tertiary educational constitution were significantly associated with adherence to modern contraceptive methods. Conversely, tribe and year of study were not significantly associated with adherence to the use of modern contraceptive methods.

Table 6 summarizes the results of logistic regression to determine which of the student characteristics predicted preferences for and adherence to modern contraceptives. Only those variables found to be significantly associated with preferences for and adherence to modern contraceptives in the bivariate analysis were included in the logistic regression analysis. The results showed that receiving information from health personnel, media, or workshops (odds ratio 9.54, 95\% confidence interval 3.5-26.3), health science-related course of study (odds ratio 3.5, 95\% confidence interval 1.3-9.6), and previous sexual exposure prior to university admission (odds ratio 3.48 , 95\% confidence interval 1.5-8.0) all increased the likelihood of adherence to modern contraceptives, while age group, year of study, and Christian denomination had no significant predictive effect.

\section{Discussion}

This study evaluated contraceptive preferences and adherence among unmarried sexually active students of tertiary educational institutions in a city in South East Nigeria. In particular, the study focused on preferences for and adherence to modern contraceptives, which are generally more reliable than traditional methods and some of which can prevent pregnancy as well as sexually transmitted infections.

This study showed a high level of sexual activity among both male and female students. This finding agrees with the results of previous studies in Nigeria which have documented rates of sexual activity among students of tertiary educational institutions ranging from $50 \%-86 \%{ }^{2,7,8,11,14}$ The level of sexual activity in this study is, however, specific to unmarried students unlike some previous studies which made no distinction between married and unmarried students. . $7,8,10,15,16$ The high level of sexual activity makes this group of students a suitable sample to study contraceptive use.

It is expected that contraceptive use or uptake would depend on the knowledge of available methods and the willingness to use them. Accurate knowledge of use - different from mere awareness of the names of methods - should permit appropriate use of methods. When students were asked to describe how they would use any two methods of contraception, their answers showed a low level of knowledge and understanding of the use modern (artificial) methods. A similar finding has also been documented in previous studies, most of which evaluated knowledge of the timing for the use of emergency contraception among university students In this study, approximately $34 \%$ could correctly describe two modern methods of contraception; however, Aziken et al in Benin, Nigeria found that only $18 \%$ of female students understood correctly how to use emergency contraception. ${ }^{13}$ Similar low levels of knowledge were found by Ezebialu and 
Table 4 Results of the bivariate analysis to determine the association between sociodemographic characteristics of a sample of undergraduate students in Enugu with preferences for modern contraceptive methods

\begin{tabular}{|c|c|c|c|c|}
\hline \multirow[t]{2}{*}{ Characteristic } & \multicolumn{2}{|c|}{$\begin{array}{l}\text { Preference for modern } \\
\text { contraceptive methods }(n=266)\end{array}$} & \multirow[t]{2}{*}{ Chi-square } & \multirow[t]{2}{*}{$P$-value } \\
\hline & Yes, n (\%) & No, n (\%) & & \\
\hline Age & & & 11.5 & $<0.01 *$ \\
\hline$<20$ years & $28(10.5)$ & $18(6.8)$ & & \\
\hline$\geq 20$ years & $75(28.2)$ & $145(54.5)$ & & \\
\hline Christian denomination & & & 10.4 & $<0.01 *$ \\
\hline Roman Catholics & $30(11.3)$ & $80(30.1)$ & & \\
\hline Non-Catholics & $73(27.4)$ & $83(31.2)$ & & \\
\hline Course of study & & & 47.9 & $<0.0 I^{*}$ \\
\hline Health science related & $86(32.3)$ & $55(20.7)$ & & \\
\hline Non-health science related & $27(10.2)$ & $108(40.6)$ & & \\
\hline Year of study & & & 43.6 & $<0.0 I^{*}$ \\
\hline First and second years & $42(15.8)$ & $12(4.5)$ & & \\
\hline Third and fourth years & $61(22.9)$ & I5I (56.8) & & \\
\hline Tribe & & & 1.4 & 0.24 \\
\hline Igbo & $85(31.9)$ & $143(53.8)$ & & \\
\hline Non-lgbo & $18(6.8)$ & $20(7.5)$ & & \\
\hline Previous sexual exposure & & & 27.8 & $<0.0 I^{*}$ \\
\hline Sexually exposed & $52(19.5)$ & $32(12.0)$ & & \\
\hline Not sexually exposed & $51(19.2)$ & $|3|(49.2)$ & & \\
\hline Source of contraceptive information & & & 98.1 & $<0.0 I^{*}$ \\
\hline Friends & $9(3.4)$ & 117 (43.9) & & \\
\hline Media/health worker/workshop & $94(35.3)$ & $46(17.3)$ & & \\
\hline
\end{tabular}

Note: *Significant at $P<0.05$.

Table 5 Results of the bivariate analysis to determine the association between sociodemographic characteristics of a sample of undergraduate students in Enugu with adherence to use of modern contraceptive methods

\begin{tabular}{|c|c|c|c|c|}
\hline \multirow[t]{2}{*}{ Characteristic } & \multicolumn{2}{|c|}{$\begin{array}{l}\text { Adherence to modern } \\
\text { contraceptive methods }(n=103)\end{array}$} & \multirow[t]{2}{*}{ Chi-square value } & \multirow[t]{2}{*}{$P$-value } \\
\hline & Yes, n (\%) & No, n (\%) & & \\
\hline Age & & & 3.4 & 0.06 \\
\hline$<20$ years & $6(5.8)$ & $8(7.8)$ & & \\
\hline$\geq 20$ years & $18(17.5)$ & $71(68.9)$ & & \\
\hline Religion & & & 2.3 & 0.12 \\
\hline Christian & $17(16.5)$ & $67(65.0)$ & & \\
\hline Non-Christian & $7(6.8)$ & $12(11.7)$ & & \\
\hline Christian denomination & & & 6.0 & $0.01 *$ \\
\hline Catholic & $4(3.9)$ & $35(33.9)$ & & \\
\hline Non-Catholic & $20(19.4)$ & $44(42.7)$ & & \\
\hline Tribe & & & 0.2 & 0.6 \\
\hline Igbo & $19(18.4)$ & $66(64.1)$ & & \\
\hline Non-lgbo & $5(4.9)$ & $13(12.6)$ & & \\
\hline Course of study & & & 10.5 & $<0.0$ I* \\
\hline Health science related & $20(19.4)$ & $36(34.9)$ & & \\
\hline Non-health science related & $4(3.9)$ & $43(4 I .7)$ & & \\
\hline Year of study & & & 0.10 & 0.74 \\
\hline First and second year & $5(4.9)$ & $19(18.4)$ & & \\
\hline Third and fourth year & $19(18.4)$ & $60(58.3)$ & & \\
\hline Previous sexual exposure & & & 18.2 & $<0.01 *$ \\
\hline Sexually exposed & $24(23.3)$ & $4 \mathrm{I}(39.8)$ & & \\
\hline Not sexually exposed & $0(0.0)$ & $38(36.9)$ & & \\
\hline Source of contraceptive information & & & 17.2 & $<0.01 *$ \\
\hline Friends & $6(5.8)$ & $57(55.3)$ & & \\
\hline Media/health worker/workshop & $18(17.50)$ & $22(21.4)$ & & \\
\hline
\end{tabular}

Note: *Significant at $P<0.05$. 
Table 6 Results of the logistic regression to determine the factors that predicted adherence to modern contraceptives among students of tertiary educational institutions in Enugu, Nigeria

\begin{tabular}{|c|c|c|c|c|}
\hline Factor & B & $P$-value & $\begin{array}{l}\text { Odds ratio, } \\
\exp (B)\end{array}$ & $\begin{array}{l}95 \% \text { confidence } \\
\text { interval }\end{array}$ \\
\hline \multicolumn{5}{|l|}{ Age group } \\
\hline \multicolumn{5}{|l|}{$\leq 20$ years $^{\dagger}$} \\
\hline$>20$ years & -0.17 & 0.47 & 0.85 & $0.54-1.33$ \\
\hline \multicolumn{5}{|l|}{ Christian denomination } \\
\hline \multicolumn{5}{|l|}{ Non-Catholic ${ }^{\dagger}$} \\
\hline Catholic & 0.21 & 0.13 & 1.24 & $0.94-1.63$ \\
\hline \multicolumn{5}{|l|}{ Course of study } \\
\hline \multicolumn{5}{|l|}{ Non-health science related ${ }^{\dagger}$} \\
\hline Health science related & 1.26 & $0.01 *$ & 3.53 & $1.3-9.6$ \\
\hline \multicolumn{5}{|l|}{ Year of study } \\
\hline \multicolumn{5}{|l|}{ First and second year ${ }^{\dagger}$} \\
\hline Third and fourth year & 0.87 & 0.11 & 2.38 & $0.82-6.90$ \\
\hline \multicolumn{5}{|l|}{ Previous sexual exposure } \\
\hline \multicolumn{5}{|l|}{ No previous sexual exposure ${ }^{\dagger}$} \\
\hline Previously sexually exposed & 1.25 & $<0.0 I^{*}$ & 3.48 & $1.52-7.96$ \\
\hline \multicolumn{5}{|l|}{ Source of contraceptive information } \\
\hline \multicolumn{5}{|l|}{ Friends/other informal sources ${ }^{\dagger}$} \\
\hline Media/health worker/workshop & 2.26 & $<0.01 *$ & 9.54 & $3.46-26.32$ \\
\hline
\end{tabular}

Notes: ${ }^{\dagger}$ Reference variable. *Significant at $P<0.05$.

Eke in Uli, Anambra state, Nigeria. ${ }^{10}$ All these suggest that the understanding of how to use contraceptives may lag behind mere awareness of the names of methods of contraception among students of tertiary educational institutions in Nigeria. It is arguable that a low level of knowledge - as was found in this study - could have contributed to the low preferences for modern contraceptive methods.

An important finding that may be related to the low level of knowledge of contraceptive methods is the quality of contraceptive information that might have been available to students. This study found that an overwhelming proportion of students obtained the information that enabled them to make choices about contraception from peers. This is similar to the findings of studies in other parts of Nigeria. For instance, in the study by Ezebialu and Eke, $51 \%$ of students obtained contraceptive information from friends, whereas in the study by Abiodun and Balogun in Ilorin, approximately $74 \%$ obtained contraceptive information from friends. ${ }^{7,10}$ It would appear, therefore, that contraceptive information among students in tertiary institutions of learning in Nigeria is largely peer-driven. With an apparent low level of knowledge of contraceptives among young people, a high dependency on peer information by young people could result in the poor uptake of modern methods of contraception or the use of nonpharmacological agents or offlabel drug use with unproven contraceptive efficacy.

To obtain optimal effectiveness from modern contraceptives, consistent and correct use of contraceptives is necessary. Adherence - as defined by this study - approximates consistent contraceptive use. This study found that similar to the level of preference for modern contraceptives, the level of adherence was also low. In addition, a substantial proportion of current users stated that they intended to discontinue use of modern methods due to the fear of perceived complications. Surprisingly, the most feared perceived complications stated by students - infertility and cancer - are not recognized as direct complications of modern contraceptives. Again, this points to the inaccuracy of contraceptive information available to students. To overcome the problems of inaccurate and deficient contraceptive information held by students, actively exposing students to adequate and correct information would be a practical solution.

Of the factors that were associated with preferences for and adherence to modern contraceptives, only three could predict the adherence of students to modern contraceptives: sourcing information from formal sources such as health workers, media, and workshops, previous sexual exposure prior to admission to a tertiary educational institution, and participating in health sciences. Both formal sources of contraceptive information and a health science-related course of study probably most likely operate through increasing the likelihood of exposure to scientific and correct information about modern contraceptives. This would be expected to foster understanding of the importance of modern contraception, and therefore facilitate their consistent use. Prior sexual exposure could have made it possible for affected students to appreciate the drawbacks in either failing to adhere to modern 
contraceptives or in resorting to unproven methods like use of nonpharmacological agents for contraception.

The strengths of this study include its community-based design and the inclusion of only unmarried on-campus students, which ensured that the true scenario of life in the institutions' campuses could be captured by the study. The drawbacks include the small number of sampled students in relation to the population of on-campus students in the three schools, and the reliance on self-reports by students, which has the potential for falsified or exaggerated responses. The authors attempted to overcome the problem of sample size versus on-campus student population by estimating the minimum number of students that needed to be sampled to obtain a sexual activity level of over $75 \%$ as reported in a previous study in this area. ${ }^{2}$

Despite these drawbacks, it can be concluded that there was a low level of knowledge of modern contraceptives among the students sampled. This most likely reflects a low level of knowledge of modern contraceptives among young people in the general population. There was also an overwhelming reliance of students on their peers for contraceptive information. In the context where accurate knowledge of contraceptive information was lacking among young people, reliance on peers for contraceptive information and advice would most likely result in misinformation, which could have been reflected by the low preferences for modern contraceptives, and recourse to nonpharmacological agents and off-label drug use for contraception. It is recommend that programs aimed at stemming the tides of unwanted pregnancy, illegal abortion, and sexually transmitted infections among young people in tertiary educational institutions must focus on increasing the content and adequacy of correct and accurate contraceptive information among them. Health worker-led, student-organized workshops or social forums would be good avenues to reach a large segment of students with accurate and adequate contraceptive information.

\section{Disclosure}

The authors report no conflicts of interest in this work.

\section{References}

1. United Nations. The United Nations Programme on Youth. 2010. New York, NY: United Nations; Available from: http://social.un.org/ youthyear/docs/UNPY-presentation.pdf. Accessed April 20, 2014.

2. Okafor II, Obi SN. Sexual risk behaviour among undergraduate students in Enugu, Nigeria. J Obstet Gynaecol. 2005;25(6):592-595.

3. Iyoke CA, Lawani OL, Ezugwu FO. Trends in complicated illegallyinduced abortion in a low resource Nigerian setting. Int $J$ Gynaecol Obstet. 2010;108(3):252-253.

4. Nwogu-Ikojo EE, Ezegwui HU. Abortion-related mortality in a tertiary medical centre in Enugu, Nigeria. J Obstet Gynaecol. 2007;27(8): 835-837.

5. National Agency for the Control of AIDS. Global AIDS Response: Country Progress Report: Nigeria GARPR 2012. Abuja: National Agency for the Control of AIDS; 2012. Available from: http://www. unaids.org/en/dataanalysis/knowyourresponse/countryprogressreports/ 2012countries/Nigeria\%202012\%20GARPR\%20Report\%20Revised. pdf. Accessed April 20, 2014.

6. Family planning: fact sheet no. 351 [webpage on the Internet]. Geneva: World Health Organization; 2013 [updated May 2, 2013]. Available from: http://www.who.int/mediacentre/factsheets/fs351/en/. Accessed April 22, 2014.

7. Abiodun OM, Balogun OR. Sexual activity and contraceptive use among young female students of tertiary educational institutions in Ilorin, Nigeria. Contraception. 2009;79(2):146-149.

8. Ejembi CL, Otu A. Sexual behaviour, contraceptive practice and reproductive outcomes among Nigerian university students. Journal of Community Medicine and Primary Health Care. 2004;16(2):8-16.

9. Imaledo JA, Peter-Kio OB, Asuquo EO. Pattern of risky sexual behavior and associated factors among undergraduate students of the University of Port Harcourt, Rivers State, Nigeria. Pan Afr Med J. 2012;9:97.

10. Ezebialu IU, Eke A. Knowledge and practice of emergency contraception among female undergraduates in south eastern Nigeria. Ann Med Health Sci Res. 2013;3(4):541-545.

11. Ibekwe PC, Obuna JA. Awareness and practice of emergency contraception among university students in Abakaliki, Southeast Nigeria. Niger J Clin Pract. 2010;13(1):20-23.

12. Daniel WW. Bustatrsties: A Foundation for Analysis in the Health Sciences, 7th edition. 1999, New York: John Witey and Sons.

13. Naing L, Winn T, Rusli BN. Practical issues in calculating the sample size for prevalence studies. Archives of Orofacial Sciences. 2006;1: $9-14$.

14. Aziken ME, Okonta PI, Ande ABA. Knowledge and perception of emergency contraception among female Nigerian undergraduates. Int Fam Plan Perspect. 2003;29(2):84-87.

15. Adeniji AO, Tijani AM, Owonikoko KM. Knowledge and determinants of emergency contraception use among students in tertiary institution in Osun State, Nigeria. Journal of Basic and Clinical Reproductive Sciences. 2013;2(1):46-53.

16. Ikeme AC, Ezegwui HU, Uzodimma AC. Knowledge, attitude and use of emergency contraception among female undergraduates in Eastern Nigeria. J Obstet Gynaecol. 2005;25(5):491-493.
Patient Preference and Adherence

\section{Publish your work in this journal}

Patient Preference and Adherence is an international, peer-reviewed, open access journal that focuses on the growing importance of patient preference and adherence throughout the therapeutic continuum. Patient satisfaction, acceptability, quality of life, compliance, persistence and their role in developing new therapeutic modalities and compounds to optimize

\section{Dovepress}

clinical outcomes for existing disease states are major areas of interest for the journal. This journal has been accepted for indexing on PubMed Central. The manuscript management system is completely online and includes a very quick and fair peer-review system, which is all easy to use. Visit http://www. dovepress.com/testimonials.php to read real quotes from published authors. 